\title{
Effects of thidiazuron on in vitro shoot regeneration of Morus alba
}

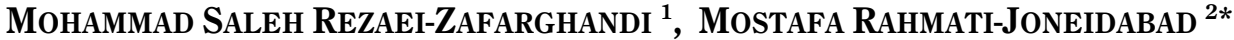 \\ ${ }^{1}$ Department of Agronomy and Plant Breeding Science, College of Aburaihan, University of Tehran, Tehran-Pakdasht, Iran \\ ${ }^{2}$ Department of Horticultural Science, Faculty of Agriculture, Agricultural Sciences and Natural Resources, \\ University of Khuzestan, Mollasani, Iran
}

\begin{abstract}
Mulberry (Morus alba L.) is an ornamental, medicinal, and fruit plant that belongs to the Moraceae family. One of the most important techniques used in plant biotechnology is tissue culture, which enables mass production of pathogen-free plants. Cotyledon has a high potential for shoot regeneration; however, to the best of our knowledge, there are no reports on plant regeneration from cotyledon explants of mulberry. Therefore, this study aimed to evaluate the potential of seedling-derived cotyledon segments to obtain shoot multiplication of mulberry. Various concentrations $(0,0.25,0.5,1,2,3$, and $4 \mathrm{mg} / \mathrm{l})$ of thidiazuron (TDZ) in combination with indole butyric acid (IBA) were used in a completely randomized design in three replications. The results showed that the highest percentage of regeneration frequency (96.67\%) and the maximum number of shoots (4.43) were obtained on Murashige and Skoog (MS) medium supplemented with $0.25 \mathrm{mg} / 1 \mathrm{TDZ}$ and $0.025 \mathrm{mg} / \mathrm{lBA}$. In the rooting experiment, the maximum rooting percentage (83.33\%) and the maximum number of roots per shoot (4.36) were obtained on MS medium containing $2 \mathrm{mg} / \mathrm{l}$ IBA. In vitro-raised plantlets were placed in pots and kept in room temperature for 30 days, and the plantlets showed more than $90 \%$ survival rate. On the basis of our results, the protocol described in this study has a high potential to be used in the micropropagation of this valuable plant.
\end{abstract}

Key words: mulberry; cotyledon; plant growth regulator; organogenesis; in vitro-grown seedlings

\section{Introduction}

In vitro propagation of plants is a useful and efficient technique that enables mass production of virus-free plants (Hesami et al., 2017a; Hesami et al., 2019a). Tissue and organ cultures have been widely used for the mass production of various plants (Hesami and Daneshvar, 2016a; Hesami et al., 2019b). Regarding the application of tissue culture techniques for the propagation of ornamental and medicinal plants, most studies have focused on two goals: mass production of plants and production of disease-free plants (Hesami and Daneshvar, 2018a; Jafari et al., 2017; Jafari et al., 2016). Indirect shoot organogenesis, as one of the methods of plant tissue culture, has some disadvantages: it is a time-consuming process and creates wide somaclonal varieties with morphological abnormalities (Hesami and Daneshvar, 2018a). In contrast, direct shoot organogenesis is an ef- ficient method for micropropagation because of its high potentiality of production of a large number of plants that are genetically identical to the mother plant, without any genetic instability and in a short time period (Hesami et al., 2017d). Shoot multiplication is affected by many factors such as plant species, growth medium, minerals, organic matter, carbohydrates, plant growth regulators (PGRs), and environmental conditions (Hesami et al., 2017c). One of the most important factors is the effect of PGRs, for example, the type and concentration of auxins and cytokinins (Hesami et al., 2017c; Hesami et al., 2019d).

Mulberry (Morus alba L.) is an ornamental, medicinal, and fruit plant that belongs to the Moraceae family. Mulberry is distributed in tropical and warm temperate regions of the world (Chitra and Padmaja, 2005). Mulberry propagation can be achieved through seeds, which

\footnotetext{
* Corresponding author: Department of Horticultural Science, Faculty of Agriculture, Agricultural Sciences and Natural Resources, University of Khuzestan, Mollasani, Iran; e-mail: rahmati@asnrukh.ac.ir
} 
may limit its large-scale production because of low seed germination and the plant's susceptibility to viral pathogens (Agarwal et al., 2004). Tissue culture is an alternative technique to control viral diseases and produce plants with high genetic uniformity (Hesami et al., 2017b; Hesami et al., 2019c). Some researchers have performed in vitro propagation of Mulberry through direct organogenesis (Agarwal et al., 2004; Chitra and Padmaja, 2005; Bhau and Wakhlu, 2001; Oka and Ohyama, 1981). For example, Chitra and Padmaja (2005) investigated direct organogenesis of Mulberry by using leaf explants. They reported that the highest percentage of shoot regeneration was obtained on Murashige and Skoog (MS) medium containing $18.17 \mu \mathrm{M}$ thidiazuron (TDZ) along with $8.88 \mu \mathrm{M}$ 6-Benzylaminopurine (BAP).

Considering the important role of the micropropagation technique in regeneration protocols, one of the goals of studies on tissue culture is to provide convenient and efficient methods for rapid organogenesis and mass production of plants under in vitro conditions, which can provide appropriate ground for other research areas such as genetic engineering (Hesami et al., 2018a; Hesami et al., 2018b). Previous studies on various plants such as Antirrhinum majus (Hesami and Daneshvar, 2016b), Tinospora cordifolia (Mridula et al., 2017), Platanus acerifolia (Bao et al., 2017), and Cucumis melo (Sebastiani and Ficcadenti 2016) have shown that cotyledon explants have a high potential for shoot proliferation. However, on the basis of the available literature, to date, there is no report on shoot proliferation of Mulberry by using cotyledon explants. Therefore, in the present study, we aimed to evaluate the potential of cotyledon explants on shoot proliferation of Mulberry by using different concentrations of growth regulators.

\section{Materials and methods}

\section{Plant material}

Seeds were collected from 35- to 40-year-old mulberry mother plants grown on Aburaihan campus, University of Tehran, Tehran-Pakdasht, Iran. To eliminate surface contamination, the seeds were washed for 30 min under tap water. The seeds were then surface sterilized with $70 \%$ ethyl alcohol for $15 \mathrm{~s}$ and then dipped in $8 \%$ sodium hypochlorite solution (with $5 \%$ active chlorine) for 4 min under a laminar air flow chamber. Then, the seeds were washed thrice in sterilized distil- led water for 3-5 min each time. To achieve seed germination and production of seedlings free from pollution and to prepare explants, the seeds after surface sterilization were cultured in a one-tenth strength MS medium, and all cultures were incubated in a culture room at $25 \pm 2{ }^{\circ} \mathrm{C}$ in light intensity of $65 \mu \mathrm{mol} \cdot \mathrm{m}^{-2} \cdot \mathrm{s}^{-1}$. Cotyledon explants were prepared from in vitro-grown seedlings (Fig. 1A).

\section{Effects of PGRs on shoot regeneration}

Cotyledon explants were cut into sections of $5-7 \mathrm{~mm}$ in length and were placed horizontally on MS medium containing $0.25,0.5,1,2,3$, and $4 \mathrm{mg} / 1 \mathrm{TDZ}$ in combination with indole butyric acid (IBA). The TDZ to IBA ratio in the medium was $10: 1$. The basic culture medium consisted of MS medium fortified with $30 \mathrm{~g} / \mathrm{l} \mathrm{su}-$ crose as the carbohydrate source and $6 \mathrm{~g} / \mathrm{l}$ agar used to solidify the medium. Before adding agar, the $\mathrm{pH}$ of the medium was adjusted to 5.8. Glassware containing the medium were sterilized in an autoclave at $121.5^{\circ} \mathrm{C}$ and $15 \mathrm{psi}$ for $20 \mathrm{~min}$. After placing the explants on the medium, the culture dishes were maintained in a growth chamber at $25 \pm 2{ }^{\circ} \mathrm{C}$ under $16 \mathrm{~h}$ photoperiod. The light intensity was $65 \mu \mathrm{mol} \cdot \mathrm{m}^{-2} \cdot \mathrm{s}^{-1}$. Parameters including regeneration rate and number of shoots were recorded after 6 weeks of growth.

\section{Root formation and acclimatization}

After the stage of organogenesis, shoots formed from cotyledon explants $(2$ to $3 \mathrm{~cm}$ ) were used for the rooting stage. MS medium modified with different concentrations $(0.5,1,1.5,2,2.5,3$, and $3.5 \mathrm{mg} / \mathrm{l})$ of IBA or 1-naphthaleneacetic acid (NAA) and MS medium without PGRs (control) were used for rooting the shoots. Parameters, including rooting frequency and number of roots per shoot, were recorded after 5 weeks of growth. Plantlets with desirable shoots and leaves as well as strong roots were transferred to sterile pots containing perlite mixed with cocopeat (ratio $1: 1$ ) for acclimatization purposes and were kept in a growth chamber for 30 days. They were finally transferred to a greenhouse, and the survival rate of plantlets was recorded.

\section{Statistical analysis}

All experiments were performed with a completely randomized design in three replications (each replication consisted of 10 samples). Statistical analysis of 


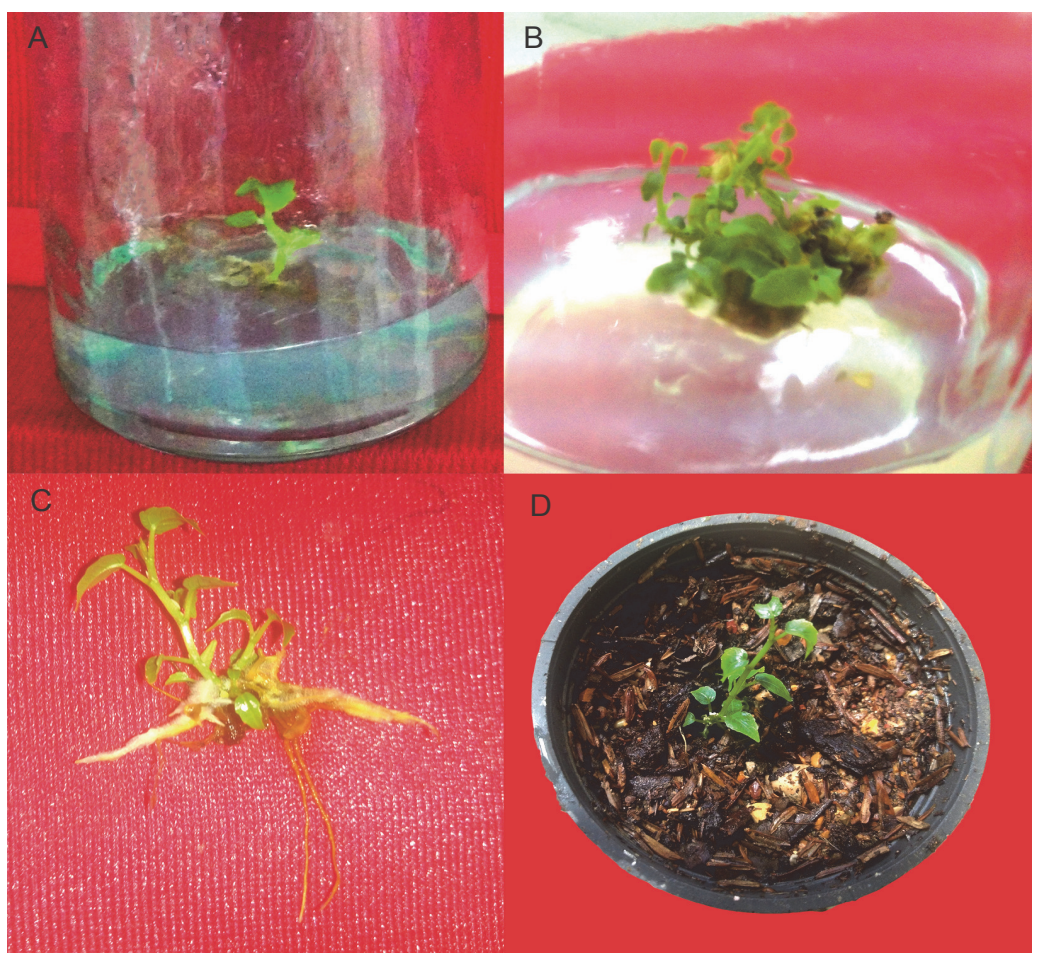

Fig. 1. In vitro plant regeneration through direct shoot organogenesis from seedling derived cotyledon segments of Mulberry. A) seedling from in vitro seed germination; B) shoot regeneration from cotyledon explant on MS + $0.25 \mathrm{mg} / \mathrm{l} \mathrm{TDZ}+0.025 \mathrm{mg} / \mathrm{l} \mathrm{IBA}$ after 6 weeks; C) in vitro root formation on MS $+2.0 \mathrm{mg} / \mathrm{l} \mathrm{IBA}$ after 5 weeks; D) acclimatized regenerated plant after 30 days

these tests was performed using SAS (9.3) software, and mean comparison was tested with Duncan's multiple range test $(P<0.05)$.

\section{Results and discussion}

\section{Effects of PGRs on shoot regeneration}

Presently, tissue culture is considered by the growers of ornamental and medicinal plants as a technique for rapid and homogeneous production of high-quality plants and for the production of pathogen-free plants at the commercial level (Hesami et al., 2018b; Hesami et al., 2018c; Hesami and Daneshvar, 2018b). Production of lateral shoots is one of the important parameters in tissue culture because lateral shoots can be separated in the subculture stage and each one can be cultured as a separate sample, thereby increasing the proliferation speed (Jaiswal and Narayan, 1985). Regeneration is an extremely complex process that is affected by multiple qualitative and quantitative factors such as genotype; culture medium; PGRs (Hesami and Daneshvar, 2018b); agar; type, size, age, and position of explants; and duration of light intensity (Hesami et al., 2017d). Exogenous PGRs can stimulate cell division, cell growth, and cell differentiation in the medium (Hesami et al., 2017c). Thus far, few studies have been reported in the field of plantlet regeneration and effects of different concentrations of PGRs on micropropagation of Mulberry (Agarwal et al., 2004; Chitra and Padmaja, 2005; Bhau and Wakhlu, 2001; Oka and Ohyama, 1981). In the present study, different concentrations of TDZ in combination with an auxin (IBA) showed different effects on shoot regeneration of cotyledon explants (Table 1). After 6 weeks of culturing Mulberry explants in different hormonal combination treatments, the explants showed different rates of regeneration. The present results showed that the highest regeneration rate of cotyledon explants from Mulberry (96.667\%) and the highest number of shoots (4.43) were achieved in MS medium supplemented with $1.5 \mathrm{mg} / 1 \mathrm{BAP}$ and $0.15 \mathrm{mg} / \mathrm{lBA}$ (Fig. 1B). No regeneration response was recorded in the explants cultured on basal MS medium without PGRs (control treatment) 
Table 1. Effect of TDZ in combination with IBA in Murashige and Skoog (MS) medium on regeneration response of Mulberry from cotyledon explant

\begin{tabular}{c|c|c|c}
\hline \multicolumn{2}{c|}{ Plant growth regulators $[\mathrm{mg} / \mathrm{l}]$} & $\begin{array}{c}\text { Regeneration frequency } \\
{[\%]}\end{array}$ & $\begin{array}{c}\text { Number of shoots } \\
\text { per explant }\end{array}$ \\
\hline TDAZ & IBA & $0.00^{\mathrm{e}}$ & $0.00^{\mathrm{f}}$ \\
\hline- & - & $96.667^{\mathrm{a}}$ & $4.43^{\mathrm{a}}$ \\
\hline 0.25 & 0.025 & $93.333^{\mathrm{a}}$ & $4.26^{\mathrm{a}}$ \\
\hline 0.5 & 0.05 & $83.333^{\mathrm{ab}}$ & $3.63^{\mathrm{b}}$ \\
\hline 1.0 & 0.1 & $76.667^{\mathrm{b}}$ & $3.50^{\mathrm{b}}$ \\
\hline 1.5 & 0.15 & $63.333^{\mathrm{c}}$ & $2.86^{\mathrm{c}}$ \\
\hline 2.0 & 0.2 & $53.333^{\mathrm{cd}}$ & $2.56^{\mathrm{d}}$ \\
\hline 3.0 & 0.3 & $46.667^{\mathrm{d}}$ & $1.93^{\mathrm{e}}$ \\
\hline 4.0 & 0.4 & &
\end{tabular}

Means in each column followed by the same letters are not significantly different according to Duncan's multiple range test at $P<0.05$

Table 2. Effect of auxins (IBA or NAA) in Murashige and Skoog (MS) medium on in vitro root induction in regenerated shoots of Mulberry

\begin{tabular}{c|c|c|c}
\hline \multicolumn{2}{c|}{ Plant growth regulators [mg/l] } & $\begin{array}{c}\text { Rooting frequency } \\
{[\%]}\end{array}$ & $\begin{array}{c}\text { Number of roots } \\
\text { per shoot }\end{array}$ \\
\hline IBA & NAA & $0.00^{\mathrm{g}}$ & $0.00^{\mathrm{j}}$ \\
\hline- & - & $43.33^{\mathrm{de}}$ & $2.46^{\mathrm{f}}$ \\
\hline 0.5 & - & $53.33^{\mathrm{cd}}$ & $2.86^{\mathrm{de}}$ \\
\hline 1.0 & - & $63.33^{\mathrm{bc}}$ & $3.40^{\mathrm{b}}$ \\
\hline 1.5 & - & $83.33^{\mathrm{a}}$ & $4.36^{\mathrm{a}}$ \\
\hline 2.0 & - & $73.33^{\mathrm{ab}}$ & $3.16^{\mathrm{bc}}$ \\
\hline 2.5 & - & $36.66^{\mathrm{ef}}$ & $1.70^{\mathrm{h}}$ \\
\hline 3.0 & - & $26.66^{\mathrm{f}}$ & $1.56^{\mathrm{h}}$ \\
\hline 3.5 & - & $53.33^{\mathrm{cd}}$ & $2.23^{\mathrm{g}}$ \\
\hline- & 0.5 & $63.33^{\mathrm{bc}}$ & $2.70^{\mathrm{e}}$ \\
\hline- & 1.0 & $73.33^{\mathrm{ab}}$ & $3.03^{\mathrm{cd}}$ \\
\hline- & 1.5 & $76.66^{\mathrm{ab}}$ & $3.23^{\mathrm{bc}}$ \\
\hline- & 2.0 & $56.66^{\mathrm{cd}}$ & $2.73^{\mathrm{e}}$ \\
\hline- & 2.5 & $36.66^{\mathrm{ef}}$ & $1.80^{\mathrm{h}}$ \\
\hline- & 3.0 & $26.66^{\mathrm{f}}$ & $1.23^{\mathrm{i}}$ \\
\hline- & 3.5 & & \\
\hline
\end{tabular}

Means in each column followed by the same letters are not significantly different according to Duncan's multiple range test at $P<0.05$

(Table 1). This study showed that the regeneration rate and the number of shoots were significantly reduced when the concentration of TDZ increased from 0.25 to $4.0 \mathrm{mg} / \mathrm{l}$ (Table 1). Similar to our results, Chitra and Padmaja (2005) reported that the highest percentage of shoot regeneration of Mulberry was obtained on MS medium containing $18.17 \mu \mathrm{M} \mathrm{TDZ}$ and $8.88 \mu \mathrm{M}$ BAP. However, Hesami et al. (2017b) reported that the highest shoot regeneration of Ficus religiosa via shoot tip explants was observed in MS medium supplemented 
with $1 \mathrm{mg} / \mathrm{lTDZ}$. Generally, the differences between the regeneration rate in the abovementioned studies may be due to the source, age, and endogenous content of PGRs of the explants (Thaniarasu et al., 2016). Shoot organogenesis was, however, decreased with an increase in TDZ concentration (over $0.25 \mathrm{mg} / \mathrm{l}$ ) probably because the high concentration of TDZ was unsuitable for shoot growth. Many studies have proved that TDZ has an immense potential in shoot regeneration, especially in woody plants (Ahmad and Anis, 2007; Mansouri and Preece, 2009; Siwach and Gill, 2011). However, Bosela and Michler (2008) and Feng et al. (2010) debated this view and stated that the use of TDZ above the threshold level with prolonged incubation has an adverse impact on shoot regeneration and results in shoots being deformed and exhibiting different levels of hyperhydration. The balance between auxins and cytokinins is an important morphogenic factor for the initial growth of shoots (Hesami et al., 2017c). The differentiation process is also regulated by the relative concentration of auxins and cytokinins in the growth medium (Hesami and $\mathrm{Da}-$ neshvar, 2018b). Zhao et al. (2010) reported that auxins are involved in DNA replication and cytokinins are necessary for plant cell division. In general, cytokinins play multiple roles in the control of plant development, such as cell cycle in plant cells, initiation and lateral meristem activity, RNA and protein synthesis, and stimulation and activation of enzymes involved in the development of plants (Cheng et al., 2013).

\section{Effect of IBA or NAA on root formation}

Rooting is a crucial step in the success of micropropagation (Jafari et al., 2017). Without an effective root system, plant acclimatization would be difficult, and the rate of plant propagation might be severely affected. The process of root formation is influenced by a number of internal and external factors (Hesami and Daneshvar, 2018a). Among the internal factors, the most important role is ascribed to phytohormones, especially the auxins (Hesami et al., 2017c) as auxin type and concentration significantly influence root formation. Auxins (IBA or NAA) are needed only in the early stages of the emergence of new roots. They also affect the growth of newly formed roots (Dobránszki and da Silva, 2010). In our experiments, individual shoots with 2-3 leaves, $1-2 \mathrm{~cm}$ long, were separated from multiple shoot clumps and inoculated into MS basal media containing different con- centrations $(0.5,1,1.5,2,2.5,3$, and $3.5 \mathrm{mg} / \mathrm{l})$ of IBA or NAA and media without growth regulators (control) for rooting. After 5 weeks of growth, the percentage of shoots forming roots and the number of roots per shoot were recorded. The results of the effect of different PGRs on the formation of roots (Table 2) showed that the maximum percentage of rooting (83.33\%) and the maximum number of roots (4.36) were observed in MS medium supplemented with $1.0 \mathrm{mg} / \mathrm{l} \mathrm{IBA}$ (Fig. 1C). No rooting was observed in MS medium without PGRs (control) (Table 2). In this study, NAA was less effective than IBA in stimulating root formation. Likewise, Hesami et al. (2017b) reported that the highest percentage of root formation of $F$. religiosa was observed in MS medium containing $2.0 \mathrm{mg} / \mathrm{l} \mathrm{IBA}$ after 4 weeks of incubation. Previous studies used different concentrations of auxins for in vitro root formation (Agarwal et al., 2004; Chitra and Padmaja, 2005; Bhau and Wakhlu, 2001; Oka and Ohyama, 1981). Hesami and Daneshvar (2018a) and Hesami et al. (2017c) reported that $2 \mathrm{mg} / \mathrm{l}$ IBA and 0.1 $\mathrm{mg} / \mathrm{l}$ NAA were suitable for inducing the rooting of $F$. religiosa. Siwach and Gill (2011) and Siwach and Gill (2014) also reported that IBA was more appropriate than NAA and IAA in inducing the rooting process in $F$. religiosa. IBA is more stable and less sensitive to degradation and is slowly metabolized by the peroxidase enzyme; this can be one of the possible causes for better effect of IBA in root formation as compared to other auxins (Dobránszki and da Silva, 2010). In general, auxin at low concentration favors root initiation, whereas at high concentration, it induces callus formation (Hesami et al., 2017c). Thus, our study showed that the production of callus in the root formation stage could be increased exponentially by high concentrations (over $2 \mathrm{mg} / \mathrm{l}$ ) of IBA or NAA, which in turn, can exert a negative impact on roots. Thus, high concentrations of auxins can weaken the roots and destroy a high percentage of plants in the acclimatization stage. Similar results were obtained in previous studies. Kollmeier et al. (2000) reported that callus formation, at the end of the microshoots, can impair vascular connections between roots and shoots and can also prevent the absorption of water and nutrients. To sustain plant's life and increase its efficacy in various environmental conditions, it is necessary to gradually change rhizosphere to enable plants to withstand stress (Gaspar et al., 1996; Jafari et al., 2017). After 3 weeks, the plantlets were subcultured in the hor- 
mone-free medium for 2 weeks in the presence of the complete concentration of mineral elements. Subsequently, the newly formed roots were observed.

\section{Acclimatization}

According to the results of the current study, $90 \%$ of the rooted plantlets survived (Fig. 1D); this finding is somewhat in agreement with other studies (Hesami et al., 2017c; Hesami and Daneshvar, 2018a; Hassan et al., 2009; Deshpande et al., 1998; Jaiswal and Narayan, 1985; Siwach and Gill, 2011, 2014), where the authors used this method with different planting substrates for acclimatization. Siwach and Gill (2011) reported 90\% survival rate of in vitro plantlets of $F$. religiosa grown on a mixture of soil, sand, and vermiculite $(3: 1: 1)$ and obtained healthy plants.

\section{Conclusions}

The results of this study revealed that cotyledon explants had the highest regeneration rate in modified MS medium with $0.25 \mathrm{mg} / \mathrm{l} \mathrm{TDZ}$ and $0.025 \mathrm{mg} / \mathrm{l} \mathrm{IBA}$. Furthermore, our overall results showed that IBA was more effective than NAA in root formation of Mulberry. The described proliferation protocol has significant advantages such as large-scale production in a short period of time and is considered not only as an aspect of in vitro propagation of Mulberry but also as a suitable technique for breeding and gene transfer purposes.

\section{References}

Agarwal S., Kanwar K., Sharma D. (2004) Factors affecting secondary somatic embryogenesis and embryo maturation in Morus alba L. Sci. Hort. 102(3): 359-368.

Ahmad N., Anis M. (2007) Rapid clonal multiplication of a woody tree, Vitex negundo L. through axillary shoots proliferation. Agrofor. Syst. 71(3): 195-200.

Bao Z., Zhang Y., Shao C., Zhang J., Liu G., Bao M. (2017) $A$ rapid and efficient in vitro shoot regeneration protocol using cotyledons of London plane tree (Platanus acerifolia Willd.). Plant Growth Regul. 83(2): 245-252.

Bhau B., Wakhlu A. (2001) Effect of genotype, explant type and growth regulators on organogenesis in Morus alba. Plant Cell Tiss. Organ. Cult. 66(1): 25-29.

Bosela M.J., Michler C. (2008) Media effects on black walnut (Juglans nigra L.) shoot culture growth in vitro: evaluation of multiple nutrient formulations and cytokinin types. In Vitro Cell Dev. Biol. Plant. 44(4): 316-329.

Cheng Z.J., Wang L., Sun W., Zhang Y., Zhou C., Su Y.H., Li W., Sun T.T., Zhao X.Y., Li X.G. (2013) Pattern of auxin and cytokinin responses for shoot meristem induction results from the regulation of cytokinin biosynthesis by AUXIN RESPONSE FACTOR3. Plant Physiol. 161(1): 240-251.

Chitra D.V., Padmaja G. (2005) Shoot regeneration via direct organogenesis from in vitro derived leaves of mulberry using thidiazuron and 6-benzylaminopurine. Sci. Hort. 106(4): 593-602.

Deshpande S., Josekutty P., Prathapasenan G. (1998) Plant regeneration from axillary buds of a mature tree of Ficus religiosa. Plant Cell Rep. 17(6): 571-573.

Dobránszki J., da Silva J.A.T. (2010) Micropropagation of apple-a review. Biotechnol. Adv. 28(4): 462-488.

Feng J.-C., Yu X., Shang X., Li J., Wu Y. (2010) Factors influencing efficiency of shoot regeneration in Ziziphus jujuba Mill. 'Huizao’. Plant Cell Tissue Organ Cult. 101(1): 111-117.

Gaspar T., Kevers C., Penel C., Greppin H., Reid D.M., Thorpe T.A. (1996) Plant hormones and plant growth regulators in plant tissue culture. In Vitro Cell Dev. Biol. Plant. 32(4): 272-289.

Hassan A.S., Afroz F., Jahan M.A.A., Khatun R. (2009) In vitro regeneration through apical and axillary shoot proliferation of Ficus religiosa 1.-a multi-purpose woody medicinal plant. Plant Tiss. Cult. Biotech. 19(1): 71-78.

Hesami M., Daneshvar M.H. (2016a) Development of a regeneration protocol through indirect organogenesis in Chenopodium quinoa Wild. Indo-Am. J. Agric. Vet. Sci. 4(1): 25-32.

Hesami M., Daneshvar M.H. (2016b) Regeneration from callus which is produced from cotyledon of Antirrhinum majus. Indo-Am. J. Agric. Vet. Sci. 4(1): 20-24.

Hesami M., Daneshvar M.H. (2018a) In vitro adventitious shoot regeneration through direct and indirect organogenesis from seedling-derived hypocotyl segments of Ficus religiosa L.: an important medicinal plant. HortSci. 53(1): 55-61.

Hesami M., Daneshvar M.H. (2018b) Indirect organogenesis through seedling-derived leaf segments of Ficus religiosa - a multipurpose woody medicinal plant. J. Crop Sci. Biotech. 21(2): 129-136.

Hesami M., Daneshvar M.H., Lotfi A. (2017a) Effect of sodium hypochlorite on control of in vitro contamination and seed germination of Ficus religiosa. Iran. J. Plant Physiol. 7(4): 2157-2162.

Hesami M., Daneshvar M.H., Lotfi A. (2017b) In vitro shoot proliferation through cotyledonary node and shoot tip explants of Ficus religiosa L. Plant Tiss. Cult. Biotech. 27(1): 85-88.

Hesami M., Daneshvar M.H., Yoosefzadeh-Najafabadi M. (2018a) Establishment of a protocol for in vitro seed germination and callus formation of Ficus religiosa L., an important medicinal plant. Jundishapur J. Nat. Pharm. Prod. 13(4): e62682.

Hesami M., Daneshvar M.H., Yoosefzadeh-Najafabadi M. (2019a) An efficient in vitro shoot regeneration through 
direct organogenesis from seedling-derived petiole and leaf segments and acclimatization of Ficus religiosa. J. Forest. Res. 30(3): 807-815.

Hesami M., Daneshvar M.H., Yoosefzadeh-Najafabadi M., Alizadeh M. (2017c) Effect of plant growth regulators on indirect shoot organogenesis of Ficus religiosa through seedling derived petiole segments. J. Gen. Eng. Biotech. 16(1): DOI:10.1016/j.jgeb.2017.1011.1010.

Hesami M., Naderi R., Tohidfar M. (2019b) Modeling and optimizing in vitro sterilization of Chrysanthemum via multilayer perceptron-non-dominated sorting genetic algorithmII (MLP-NSGAII). Front. Plant Sci. 10: 282.

Hesami M., Naderi R., Tohidfar M., Yoosefzadeh-Najafabadi M. (2019c) Application of adaptive neuro-fuzzy inference system-non-dominated sorting genetic algorithm-II (ANFISNSGAII) for modeling and optimizing somatic embryogenesis of Chrysanthemum. Front. Plant Sci. 10: 869.

Hesami M., Naderi R., Yoosefzadeh-Najafabadi M. (2018b) Optimizing sterilization conditions and growth regulator effects on in vitro shoot regeneration through direct organogenesis in Chenopodium quinoa. BioTechnologia 99(1): 49-57.

Hesami M., Naderi R., Yoosefzadeh-Najafabadi M., Maleki M. (2018c) In vitro culture as a powerful method for conserving Iranian ornamental geophytes. BioTechnologia 99(1): 73-81.

Hesami M., Naderi R., Yoosefzadeh-Najafabadi M., Rahmati M. (2017d) Data-driven modeling in plant tissue culture. J. Appl. Environ. Biol. Sci. 7(8): 37-44.

Hesami M., Tohidfar M., Alizadeh M., Daneshvar M.H. (2019d) Effects of sodium nitroprusside on callus browning of Ficus religiosa: an important medicinal plant. J. Forest. Res. 31: 1-8.

Jafari M., Daneshvar M.H., Lotfi-Jalalabadi A. (2016) Control of in vitro contamination of Passiflora caerulea by using of sodium hypocholorite. Indo-Am. J. Agric. Vet. Sci. 4(2): 8-15.

Jafari M., Daneshvar M.H., Lotfi A. (2017) In vitro shoot proliferation of Passiflora caerulea $L$. via cotyledonary node and shoot tip explants. BioTechnologia 98(2): 113-119.
Jaiswal V., Narayan P. (1985) Regeneration of plantlets from the callus of stem segments of adult plants of Ficus religiosa L. Plant Cell Rep. 4(5): 256-258.

Kollmeier M., Felle H., Horst W. (2000) Is basipetal auxin flow involved in inhibition of root elongation. Plant Physiol. 122: 945-956.

Mansouri K., Preece J.E. (2009) The influence of plant growth regulators on explant performance, bud break, and shoot growth from large stem segments of Acer saccharinum $L$. Plant Cell Tiss. Organ. Cult. 99(3): 313.

Mridula K., Parthibhan S., Kumar T.S., Rao M. (2017) In vitro organogenesis from Tinospora cordifolia (Willd.) Miers-A highly valuable medicinal plant. South Afr. J. Bot. 113: 84-90.

Oka S., Ohyama K. (1981) In vitro initiation of adventitious buds and its modification by high concentration of benzyladenine in leaf tissues of mulberry (Morus alba). Can. J. Bot. 59(1): 68-74.

Sebastiani M.S., Ficcadenti N. (2016) In vitro plant regeneration from cotyledonary explants of Cucumis melo L. var. cantalupensis and genetic stability evaluation using $R A P D$ analysis. Plant Cell Tiss. Org. Cult. 124(1): 69-79.

Siwach P., Gill A.R. (2011) Enhanced shoot multiplication in Ficus religiosa $L$. in the presence of adenine sulphate, glutamine and phloroglucinol. Physiol. Mol. Biol. Plants. 17(3): 271-280.

Siwach P., Gill A.R. (2014) Micropropagation of Ficus religiosa $L$. via leaf explants and comparative evaluation of acetylcholinesterase inhibitory activity in the micropropagated and conventionally grown plants. 3 Biotech. 4(5): 477-491.

Thaniarasu R., Kumar T.S., Rao M. (2016) Mass propagation of Plectranthus bourneae Gamble through indirect organogenesis from leaf and internode explants. Physiol. Mol. Biol. Plants. 22(1): 143-151.

Zhao Z., Andersen S.U., Ljung K., Dolezal K., Miotk A., Schultheiss S.J., Lohmann J.U. (2010) Hormonal control of the shoot stem-cell niche. Nature 465(7301): 1089-1092. 